\title{
Results from the Fourth WMO Filter Radiometer Comparison for aerosol optical depth measurements
}

\author{
Stelios Kazadzis ${ }^{1,11}$, Natalia Kouremeti ${ }^{1}$, Henri Diémoz ${ }^{2}$, Julian Gröbner ${ }^{1}$, Bruce W. Forgan ${ }^{3}$, Monica Campanelli ${ }^{4}$, \\ Victor Estellés ${ }^{5}$, Kathleen Lantz ${ }^{6}$, Joseph Michalsky ${ }^{6}$, Thomas Carlund ${ }^{7}$, Emilio Cuevas $^{8}$, Carlos Toledano $^{9}$, \\ Ralf Becker $^{10}$, Stephan Nyeki ${ }^{1}$, Panagiotis G. Kosmopoulos ${ }^{11}$, Viktar Tatsiankou ${ }^{12}$, Laurent Vuilleumier ${ }^{13}$, \\ Frederick M. Denn ${ }^{14}$, Nozomu Ohkawara ${ }^{15}$, Osamu Ijima ${ }^{15}$, Philippe Goloub ${ }^{16}$, Panagiotis I. Raptis ${ }^{11,1}$, \\ Michael Milner $^{3}$, Klaus Behrens ${ }^{10}$, Africa Barreto ${ }^{8,9,17}$, Giovanni Martucci ${ }^{13}$, Emiel Hall ${ }^{6}$, James Wendell $^{6}$, \\ Bryan E. Fabbri ${ }^{14}$, and Christoph Wehrli ${ }^{1}$ \\ ${ }^{1}$ Physikalisch-Meteorologisches Observatorium Davos, World Radiation Center, Davos, Switzerland \\ ${ }^{2}$ Aria e Atmosfera - Radiazione solare e atmosfera ARPA Valle, Saint-Christophe 11020, Italy \\ ${ }^{3}$ Standards \& Metrology, Bureau of Meteorology, Docklands Vic 3008, Australia \\ ${ }^{4}$ SACI-CNR, Via Fosso del Cavaliere 100, 00133, Rome, Italy \\ ${ }^{5}$ Department of Earth Physics and Thermodynamics, Solar Radiation and Research Unit, Univ. de València, Valencia, Spain \\ ${ }^{6}$ Cooperative Institute for Research in Environmental Studies, NOAA/ESRL/GMD, Boulder, CO 80305, USA \\ ${ }^{7}$ Swedish Meteorological and Hydrological Institute, 60176 Norrköping, Sweden \\ ${ }^{8}$ Izaña Atmospheric Research Centre, State Meteorological Agency (AEMET), Santa Cruz de Tenerife, Spain \\ ${ }^{9}$ Atmospheric Optics Group (GOA), University of Valladolid 47011, Valladolid, Spain \\ ${ }^{10}$ Deutscher Wetterdienst Meteorologisches Observatorium Lindenberg, 15848 Tauche, Germany \\ ${ }^{11}$ Institute of Environmental Research and Sustainable Development, National Observatory of Athens, Athens, Greece \\ ${ }^{12}$ COFOVO Energy Inc., 800 King Edward Avenue, Suite 3014, Ottawa, ON, K1N 6N5, Canada \\ ${ }^{13}$ Federal Office of Meteorology and Climatology MeteoSwiss, Payerne, Switzerland \\ ${ }^{14}$ Science Systems \& Applications Inc NASA Langley Science Directorate, Hampton, VA 23666, USA \\ ${ }^{15}$ Japan Meteorological Agency 1-3-4 Otemachi, Chiyoda-ku, 100-8122 Tokyo, Japan \\ ${ }^{16}$ Laboratoire d'Optique Atmosphérique, Univ. des Sciences et Technologies de Lille 159655 Villeneuve d'Ascq, France \\ ${ }^{17}$ Cimel Electronique, 75011, Paris, France
}

Correspondence: Stelios Kazadzis (stelios.kazadzis@pmodwrc.ch)

Received: 28 November 2017 - Discussion started: 6 December 2017

Revised: 2 February 2018 - Accepted: 7 February 2018 - Published: 6 March 2018

\begin{abstract}
This study presents the results of the Fourth Filter Radiometer Comparison that was held in Davos, Switzerland, between 28 September and 16 October 2015. Thirty filter radiometers and spectroradiometers from 12 countries participated including reference instruments from global aerosol networks. The absolute differences of all instruments compared to the reference have been based on the World Meteorological Organization (WMO) criterion defined as follows: "95\% of the measured data has to be within $0.005 \pm 0.001 / \mathrm{m}$ " (where $m$ is the air mass). At least 24 out of 29 instruments achieved this goal at both 500 and $865 \mathrm{~nm}$, while 12 out of 17 and 13 out of 21 achieved this at 368
\end{abstract}

and $412 \mathrm{~nm}$, respectively. While searching for sources of differences among different instruments, it was found that all individual differences linked to Rayleigh, $\mathrm{NO}_{2}$, ozone, water vapor calculations and related optical depths and air mass calculations were smaller than 0.01 in aerosol optical depth (AOD) at 500 and $865 \mathrm{~nm}$. Different cloud-detecting algorithms used have been compared. Ångström exponent calculations showed relatively large differences among different instruments, partly because of the high calculation uncertainty of this parameter in low AOD conditions. The overall low deviations of these AOD results and the high accuracy of reference aerosol network instruments demonstrated 
a promising framework to achieve homogeneity, compatibility and harmonization among the different spectral AOD networks in the near future.

\section{Introduction}

Growing recognition of the role of atmospheric aerosols in the determination and modification of the Earth's radiation budget and hydrological cycle through their direct and indirect effects has led to a steady increase of scientific interest in aerosol physical, chemical and optical properties over the last decades (Augustine et al., 2008; Lohmann and Feichter, 2005; Nyeki et al., 2012; Wehrli, 2008). The main parameter related to columnar integrated optical activity of aerosols is their optical depth, which can be derived from ground-based measurements of the attenuation of sunlight but also from modeling of scattered radiation observed from space (e.g., Levy et al., 2013; Sayer et al., 2012; Kahn et al., 2005; Li et al., 2014; Toledano et al., 2011). Aerosol optical depth (AOD) is the single most comprehensive variable to assess the aerosol load of the atmosphere and the most important aerosol-related parameter for radiative forcing studies. This significance is illustrated by the fact that AOD is one of the core aerosol parameters of the World Meteorological Organization (WMO, 2003) Global Atmosphere Watch (GAW) program.

AOD can be derived from the ground with measurements of the spectral transmission of direct solar radiation by various types of instruments such as sun-pointing or rotating shadow-band filter radiometers, as well as spectroradiometers. It can be determined as the difference between the observed total optical depth and the modeled optical depths of molecular (Rayleigh) scattering and gaseous absorption, which depend on wavelength. Since AOD is often a small difference between two larger numbers (mainly the total optical depth and the Rayleigh scattering), it is very sensitive to small calibration errors and to a lesser degree to the chosen algorithms for the modeled components. The main source of error in sun photometry is the use of incorrectly estimated calibration constants, $V_{0}(\lambda)$. The calibration constant, the so-called exoatmospheric value, is the signal or voltage, $V_{0}(\lambda)$, that the filter radiometers and spectroradiometers would measure in the absence of an attenuating atmosphere, as if it were measuring at the top of the atmosphere. The constant is commonly determined through Langley extrapolations, which can achieve a relative uncertainty of $1 \%$ or better in the ultraviolet-A (UV-A to near-infrared (IR) spectral range (Schmid and Wehrli, 1995; Holben et al., 1998; Kazadzis et al., 2018). The Langley method consists of performing sun photometer measurements at different optical air masses (where optical air mass is defined as the direct optical path length through the aerosols of the Earth's atmosphere, throughout a day under very stable atmospheric conditions and pristine skies) and plotting the logarithm of these voltages against the air mass. The determination of $V_{0}(\lambda)$ values by the Langley method has been the main current practice for calibration of spectral radiometers used in AOD observations. In addition, other in situ calibrations (Nakajima et al., 1996; Campanelli et al., 2004, 2007) have been proposed. According to the Beer-Lambert-Bouguer law, the ordinate intercept yields the logarithm of the zero-air-mass photometer voltage $V_{0}(\lambda)$ if the turbidity of the atmosphere remains constant during the measurements (Dirmhirn et al., 1993). Langley extrapolation relies on the assumption of stable optical depth during the period of measurements. Standard leastsquares fitting techniques are applicable only under the additional assumption of a normal distribution of optical depth fluctuations. However, certain cases of systematic variation of the AOD can induce unnoticed systematic errors in the calibration constant (Shaw, 1976), which may lead to a significant day-to-day scatter. Langley extrapolations are thus rarely successful at most observation sites and are usually performed at high-altitude sites or at places where an additional independent assessment of AOD variation can be used. Although the stability of optical interference filters has improved a lot over the last 20 years, periodic recalibrations of filter radiometers are still needed in order to maintain AOD uncertainties within certain limits.

Surface-based global networks of AOD measurements, such as the AErosol RObotic NETwork (AERONET) (Holben et al., 1998, 2001), the Global Atmospheric Watch Precision Filter Radiometer network (GAW-PFR) (McArthur et al., 2003; Wehrli, 2005), the SKYradiometer NETwork (SKYNET) (Aoki et al., 2006; Kim et al., 2008), the Bureau of Meteorology AOD Australian network (Mitchell and Forgan, 2003) and the National Oceanic and Atmospheric Administration Earth System Research Laboratory's (NOAA ESRL) Surface Radiation network (SURFRAD) (Augustine et al., 2000) and NOAA ESRL global baseline observatories (Dutton et al., 1994) are used to measure spectral AODs at various locations worldwide. Several AOD intercomparison campaigns with the participation of different instrument types that belong to some of the above networks have taken place as short-term intensive field campaigns and have proven themselves a successful method of relating the methodologies of standards from one network to another (Aoki et al., 2006; Kim et al., 2005; McArthur et al., 2003; Mitchell and Forgan, 2003; Schmid et al., 1999).

Simultaneously, most of the previous AOD comparison studies, including the first, second and third filter radiometer comparisons (FRC-I, FRC-II and FRC-III), were conducted under clear atmospheric conditions, which are preferred for evaluating the differences in instrument calibrations. Results from FRC-I to III were not published as the intercomparisons were effectively organized on an ad hoc basis amongst participants of the International Pyrheliometer Comparisons (IPCs) at the Physikalisch-Meteorologisches Observatorium Davos, World Radiation Center (PMOD/WRC), 
Davos, Switzerland. FRC-I to FRC-III were held for 2 weeks in September-October 2000, 2005 and 2010, respectively. FRC-II and FRC-III were based on AOD results derived from simultaneous measurements by each participant according to their standard protocol and evaluated by their preferred algorithms, including cloud screening. Recommendations by WMO experts (WMO, 2005) were implemented as of FRCII. A large number of radiometers were present during both FRC-II (14 from 9 countries) and FRC-III (17 from 10 countries). The main conclusions were as follows: (i) most of the ground-based AOD-measuring instruments were able to achieve comparable results to within $\approx \pm 0.005$, (ii) algorithms used for calibration and evaluation contributed a significant fraction of the observed dispersion in AOD measurements and (iii) measurements of the Angström exponent (AE) for the wavelength pair 500/862 nm were questionable when $\mathrm{AOD}<0.1$.

In this study, we present the results of the Fourth FRC intercomparison campaign in which 30 instruments, from 12 countries, belonging to the above-mentioned global or national networks, participated. Section 2 presents the instrumentation, the location of measurements and the analytical methodology used. Section 3 describes the intercomparison results, while conclusions in Sect. 4 investigate AOD calculation methods and assumptions involved and set the framework within which the homogeneity of networks will be feasible through standardization of instrumentation and procedures in combination with a multi-faceted data quality control and quality assurance system. The whole activity aims to homogenize and harmonize AOD measurements on a global scale. The comparison protocol was formulated according to the WMO recommendations (WMO, 2003, 2005).

\section{Instrument, location and AOD retrieval}

\subsection{Intercomparison location}

The World Optical depth Research and Calibration Center (WORCC) was established at Davos in 1996 and was assigned the mission by WMO to develop stable instrumentation and improved methods for calibration and observation of AOD. These new developments were demonstrated in a global pilot network (Wehrli, 2008). Toward this goal and concurrent with the 12th International Pyrheliometer Comparison (IPC-XII), FRC-IV was held. Representatives for instrumentation belonging to different aerosol optical depth global networks were invited to participate. The comparison took place on the premises of the PMOD/WRC from 28 September to 16 October 2015. Thirty filter radiometers and spectroradiometers from 12 countries participated in this campaign. PMOD/WRC $\left(46^{\circ} 49^{\prime} \mathrm{N}, 9^{\circ} 51^{\prime} \mathrm{E} ; 1590 \mathrm{~m}\right.$ above sea level) is situated at the edge of the small town of Davos in the eastern part of Switzerland. The valley of Davos is oriented northeast-southwest and the horizon limits solar observations to zenith angles smaller than about $78^{\circ}$ (from about $07: 15$ to $16: 15 \mathrm{CET}$ ) in fall. Average sunshine duration in September and October is 173 and $156 \mathrm{~h}$, respectively, while average long-term AOD at $500 \mathrm{~nm}$ is $\sim 0.06$ at $500 \mathrm{~nm}$ (Nyeki et al., 2012).

During FRC-IV, there were 5 days (28-30 September, 1 and 12 October) mainly with sunshine and only very limited presence of clouds. Measurements from these days have been used to compare the participating instruments. During the five intercomparison days, AOD varied from 0.02 up to 0.12 at $500 \mathrm{~nm}$, which can be considered as normal values for the area. Figure 1 shows the AOD variability during the intercomparison days, as measured by the WORCC triad that is defined as the mean of three well-maintained precision filter radiometer (PFR) instruments. Before the start of the campaign, the PFR triad was intercompared with three additional PFR instruments that had performed measurements at stations in Izaña, Tenerife, Spain, (two instruments) and Mauna Loa, Hawaii, United States, for a period of 9 months. The calibration of the particular instruments was based on the Langley calibration technique. During five cloudless days in August-September 2015, the three Langley-calibrated instruments were compared with the three PFR triad instruments. The differences in AOD for all instruments were from 0.2 to $0.5 \%$ or up to 0.0005 in AOD at all wavelengths.

\subsection{Participating instruments}

Filter radiometers have been used in meteorology for at least 40 years to measure atmospheric haze or turbidity. Modern sun photometers use dielectric interference filters and silicon photodetectors resembling the filter radiometers used in metrology. The PFRs (Wehrli, 2000) have been designed with emphasis on radiometric stability and a small number of instruments were built for a trial network of AOD measurement sites (Wehrli, 2005).

The participating filter radiometers were either of the direct pointed type, e.g., classic sun photometers, including sky-scanning radiometers used in direct sun mode, or hemispherical rotating shadow-band radiometers. These included the following (see Table 1 for further details).

Nine instruments were of the PFR type (manufactured by PMOD/WRC) that is used in the GAW AOD network (Wehrli, 2005). The PFR is a classic sun photometer with four independent channels and a field of view (FoV) of $2.5^{\circ}$ and that is equipped with 3 to $5 \mathrm{~nm}$ bandwidth interference filters. The detector unit is held at a constant temperature of $20^{\circ} \mathrm{C}$ by an active Peltier system.

Two radiometers were of the Carter-Scott SP02 type (Mitchell and Forgan, 2003), which is similar to the PFR, but has a wider FoV of $5^{\circ}$ and no temperature controller.

Three Cimel (CIM) CE318 sun- and sky-scanning radiometers used by AERONET (Holben et al., 1998) were included; two of them are the CE318-T model, which is the new standard AERONET instrument with improved perfor- 


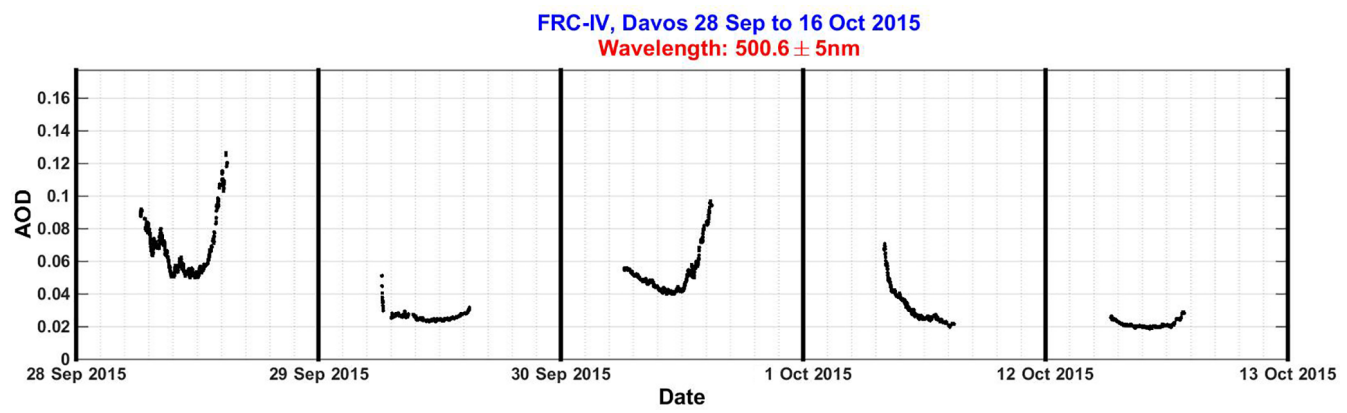

Figure 1. Average AOD at $500 \mathrm{~nm}$ measured by the three reference PFR instruments (WORCC triad) during 5 days with cloud-free sky conditions. Data points represent 1 min measurements.

mance and which is capable of performing lunar observations (Barreto et al., 2016). These instruments have a narrow FoV of $1.2^{\circ}$ and sequentially measure the sun at nine wavelengths within a few seconds. No temperature control is used.

Four Multi-Filter Rotating Shadowband Radiometer (MFRSRs) (Harrison et al., 1994, 1999) with a hemispheric FoV are used. These measure global horizontal and diffuse horizontal irradiance (GHI and DHI) in five aerosol channels; the difference in GHI and DHI divided by the solar-zenith angle is cosine-corrected to provide calculated direct beam spectral irradiances. The temperature is held near $40^{\circ} \mathrm{C}$. The effective FoV is the largest of any of the instruments in this study at $\sim 6.5^{\circ}$.

Three Precision Solar Radiometers (PSRs) are used that are direct sun-pointing spectroradiometers able to measure the spectrum from 300 to $1000 \mathrm{~nm}$ with a wavelength increment of $0.7 \mathrm{~nm}$. The FoV and the full width at half maximum (FWHM) values are $1.5^{\circ}$ and 1.5 to $6 \mathrm{~nm}$ respectively. These are manufactured by PMOD/WRC and are temperature-controlled.

Three direct sun-pointing POM-2 sky radiometers instruments from Prede Co., Ltd are included. The instruments have a FoV of $1^{\circ}$ and FWHM equal to $3 \mathrm{~nm}$ (UV), $10 \mathrm{~nm}$ (visible, VIS) and $20 \mathrm{~nm}$ (IR).

Four Solar Spectral Irradiance Meters (SSIMs) from Cofovo Energy Inc are employed. The instruments measure AOD at six wavelengths with an FoV equal to $2^{\circ}$ and an FWHM equal to $5 \mathrm{~nm}$.

One Microtops (MIC) handheld aerosol sun photometer from the Solar Light Company was employed. The instrument measures at five wavelengths between 340 and $936 \mathrm{~nm}$ with FoV and FWHM values equal to $2.5^{\circ}$ and $10 \mathrm{~nm}$, respectively.

Historically, instrument comparisons have consisted of bringing a number of instruments together to a single location for a period of several days to several weeks (e.g., Schmid et al., 1999). These types of comparisons are essential in order to try to move the frontiers of instrument and metrology science forward. However, there may be little or no relation between the results of these intensive compar- isons and the results from the same instruments when placed in an operational network setting. The comparison that is reported here provides insight into the quality of data output by instruments when attended to following operational protocols, designed by the various data centers, which are responsible for the routine handling of the measurements. Therefore, the results of this comparison should provide an understanding of both the comparability between different networks and the overall data quality of participating networks. However, in addition to these FRC-IV results, homogeneityrelated conclusions for different networks are linked with the action of each network towards standardization of calibration and instrumentation and towards the use of standard operational procedures, including data quality control and quality assurance protocols. Given the differences in instrumentation characteristics, calibration strategies (Walker et al., 1987) and processing algorithms used by different networks, the effective equivalence of AOD observations needs to be estimated through intensive observation periods (Schmid et al., 1999) or extensive field comparisons (McArthur et al., 2003; Mitchell and Forgan, 2003) of co-located instruments representing different networks.

It has to be noted that most of the instruments have been installed, maintained and checked by the initial instrument operators that participated in the campaign, with the exception of two Cimel instruments that PMOD WRC staff installed and maintained during the campaign.

\subsection{AOD retrieval}

AOD is defined as the negative natural logarithm of transmission, normalized to the vertical path length, $m=1$, through the atmosphere; its error becomes proportional to the relative error in calibration and inversely proportional to the length $m$ of a slant path. The current GAW specification (WMO, 2005) calls for an AOD uncertainty of $0.005 \pm 0.01 / \mathrm{m}$, thus requiring a calibration uncertainty of $1 \%$. This specification is similar to the uncertainty required for satellite AOD retrievals of 0.015 over land and of 0.010 over the ocean in order to make 
Table 1. Details of sun photometers used during the FRC-IV intercomparison campaign.

\begin{tabular}{|c|c|c|c|c|}
\hline $\begin{array}{l}\text { Instrument } \\
\text { type }\end{array}$ & Measuring wavelengths (nm) & $\begin{array}{l}\text { Field of } \\
\text { view }\left({ }^{\circ}\right)\end{array}$ & $\mathrm{FWHM}^{*}(\mathrm{~nm})$ & Measurement principle \\
\hline PFR-N & $368,412,500,863$ & 2.5 & $3.8-5.4$ & Sun-pointing on tracker \\
\hline Cimel & $\begin{array}{l}340,380,440,500,675,870, \\
1020,1640\end{array}$ & 1.2 & $\begin{array}{l}2.4(340,380 \mathrm{~nm}) 10 \text { (rest } \\
\text { of wavelengths) }\end{array}$ & Sun-pointing on tracker \\
\hline MFRSR & $415,500,615,673,870,940$ & $\sim 6.5$ & 10 & $\begin{array}{l}\text { Diffuse and global using shadow } \\
\text { band }\end{array}$ \\
\hline POM-2 & $\begin{array}{l}315,340,380,400,500,675 \\
870,940,1020,1627,2200\end{array}$ & 1 & $\begin{array}{l}3 \text { (UV), } 10 \text { (VIS) up to } 20 \\
\text { (IR) }\end{array}$ & Sun-pointing on tracker \\
\hline PSR & $300-1000$, step 0.7 & 1.5 & $1.5-6$ & Sun-pointing on tracker \\
\hline SP02 & $\begin{array}{l}368,412,502,675,778,812, \\
862\end{array}$ & 5 & 5 & Sun-pointing on tracker \\
\hline SSIM & $\begin{array}{l}\text { Six filters, spectral AOD re- } \\
\text { trieval }\end{array}$ & 2 & 5 & Sun-pointing on tracker \\
\hline Microtops & $340,440,500,870,936$ & 2.5 & 10 & Handheld tripod \\
\hline
\end{tabular}

* FWHM refers to the full width at half maximum.

a meaningful statement concerning the aerosol climate effect (Chylek et al., 2003).

Measurements of solar irradiance were nominally taken each full minute by the participant's data acquisition systems, typically yielding 500 observations per cloudless day. Actual sampling/averaging rates ranged from $15 \mathrm{~s}$ to 1 min depending on the instrument. Simultaneous measurements were defined in a time window of $30 \mathrm{~s}$ before and after each full CET minute. The raw measurements were evaluated by each participant according to their preferred algorithms, including cloud screening, and were then submitted for comparison. The three Cimel instruments which participated in the campaign measured at different frequencies: (i) one measurement every $3 \mathrm{~min}$, (ii) following the typical AERONET schedule, measurements every 15 min except for the Langley sequence in the morning and evening, in which AOD measurements are more frequent and (iii) measurements every $15 \mathrm{~min}$.

The set of measurements covered wavelengths between 340 and $2200 \mathrm{~nm}$. Channels at $368 \pm 3 \mathrm{~nm}, 412 \pm 3 \mathrm{~nm}$, $500 \pm 3 \mathrm{~nm}$ and $865 \pm 5 \mathrm{~nm}$ were defined as the AOD intercomparison wavelengths. The number of instruments that submitted AOD retrievals for each of those wavelengths is summarized in Table 2.

Ångström exponents were derived from optical depths at 500 and $865 \mathrm{~nm}$ (29 instruments). Values of atmospheric pressure, precipitable water, relative humidity and temperature readings were made available to all participants by the MeteoSwiss weather station located at PMOD/WRC with a $10 \mathrm{~min}$ resolution. Total ozone column content measured with a double Brewer spectroradiometer at PMOD/WRC was available as well. This common auxiliary database was available to all participants in order to avoid AOD-related discrepancies introduced by uncertainties linked with the abovementioned parameters.
Table 2. Number of instruments submitting AOD data for each wavelength during FRC-IV.

\begin{tabular}{lr}
\hline Wavelength & $\begin{array}{r}\text { Number of } \\
\text { instruments }\end{array}$ \\
\hline $368 \pm 3 \mathrm{~nm}$ & 17 \\
$412 \pm 3 \mathrm{~nm}$ & 21 \\
$500 \pm 3 \mathrm{~nm}$ & 29 \\
$865 \pm 5 \mathrm{~nm}$ & 29 \\
\hline
\end{tabular}

Several of the participating radiometers were calibrated at various sites within a few months prior to FRC-IV. Their performance during this comparison can be used to estimate the homogeneity of AOD observations across weather services, networks or individual measuring sites. For more details about the instrument acronyms, their participation in national or international aerosol networks and their basic calibration technique, see Table S1 in the Supplement.

Each of the instruments that participated in the campaign was calibrated using techniques that are quite well documented in various publications describing the instrument/network calibrations, explained more specifically in the following text.

PFR instruments. The procedure for the calibration of the reference triad is described in Kazadzis et al. (2018). Two of the other PFRs were calibrated through comparison with the triad in June 2014 and September 2015. Two PFRs were calibrated using the Langley technique for a 6-month period at stations in Izaña, Tenerife (February-August 2015), and one was calibrated using the same technique at a station in Mauna Loa, United States. Finally one PFR was calibrated through Langley-related measurements at a station in Davos, Switzerland. 
Cimel instruments. The Cimel sun photometers (no. 627 and no. 917) were calibrated by the Langley plot method at the high-altitude station in Izaña following the AERONET protocols for master instruments (Holben et al., 1998), just before the campaign (August 2015). $V_{0}$ values were calculated as the average of five different Langley calibrations in June 2015 (mean AOD at $500 \mathrm{~nm}<0.016$ during these days), following the criteria based on the coefficient of variation (CV) determined in Holben et al. (1998). These criteria require CV $<0.5 \%$ for VIS and IR spectral bands and $1 \%$ for UV wavelengths. The permanent Cimel in Davos (no. 354) was calibrated by comparison with an AERONET master instrument in June 2015, following the AERONET standard procedure for field instruments.

POM instruments. The calibration for two POM instruments is obtained every month through the improved Langley technique (Campanelli et al., 2004) at the respective stations. The method is based on the processing of almucantar measurements. It has proven to be accurate and does not require a stable aerosol optical thickness, which is necessary for a normal Langley extrapolation. One instrument was calibrated by an outdoor comparison to the Japanese Meteorological Agency (JMA) reference POM-02 (May-August 2015). The JMA reference POM-02 was calibrated using the Langley technique at the station in Mauna Loa, United States.

MFRSR instruments. SURFRAD network MFRSRs are calibrated on site using a robust estimate for $V_{0}$ s from Langleys based on at least 1 month or more of data in representative conditions (Augustine et al., 2003). MFR_US_2 and MFR_US_3 were calibrated using only the data from the FRC-IV; MFR_US_1 and MFR_DE_1 also used the data from FRC-IV for calibration following slightly different modified procedures to determine $V_{0}$ s because of the short duration of the campaign.

SPO2 instruments. The Australian Bureau of Meteorology SPO2s (Middleton Solar) were removed from a highfrequency clear-sun Australian (Longreach) station where they were calibrated in situ for 2 years using the methods described in Mitchell et al. (2017), prior to participating in the FRC.

PSR instruments. PSR instruments were absolutely calibrated at the PMOD/WRC laboratory during the campaign. In order to retrieve the AOD, an absolute extraterrestrial solar spectrum is used.

Microtops instrument. The instrument was calibrated by direct comparison with a calibrated Cimel/AERONET instrument from June to August 2015.

COFOVO instruments. The four instruments are calibrated through direct comparison with the National Renewable Energy Laboratory (United States) secondary reference spectroradiometer (Tatsiankou et al., 2013). AOD is retrieved by matching absolute irradiances at the six measuring wavelengths with a radiative transfer model.

During the intercomparison, AOD data delivered by the operators of the participating radiometers were evaluated using common comparison software. The comparison was based on AOD results only, as each operator/group used their own algorithm normally used for standard radiometer operation. The comparison principles were based on the recommendations formulated during the WMO experts workshop "Global surface network for long-term observations of column aerosol optical properties", held in 2004 in Davos (WMO, 2005), which called for the following:

- at least 1000 data points ( 1 min data) with AOD at $500 \mathrm{~nm}$ between 0.04 and 0.20

- a minimum duration of 5 days

- traceability requiring $95 \%$ uncertainty within $\pm 0.005+0.01 / m$ optical depths.

During FRC-IV, weather conditions allowed over 1000 measurements to be made for most instruments on 5 days, allowing the above-mentioned recommendations to be fulfilled.

\section{Results}

\subsection{AOD differences}

The intercomparison results presented below are based on AOD values provided by the individual instrument operators compared to the triad. Figure 2 shows an example of this comparison, on a diurnal plot, including various instruments separated into groups of different instrument types, compared to the PFR triad. The majority of the PFRs showed the best performance with absolute AOD differences from the triad ranging in all cases and wavelengths from zero to 0.01 . As the measured wavelength increases, the errors are minimized, reaching performance errors close to zero, except for some overestimated outliers for PFR_SE_N35, which were caused by nonsynchronous measurements (timing) for particular periods. Results for the three CIM instruments are almost identical to those of the PFR at 500 and $862 \mathrm{~nm}$ (Fig. 2a), while a slight underestimation on the order of 0.01 and 0.005 at the shorter wavelengths 368 and $412 \mathrm{~nm}$ (not shown here), respectively, was found. It has to be noted that Cimel AOD values at 412 and $368 \mathrm{~nm}$ have been linearly interpolated using the Cimel AOD at 340, 380 and $440 \mathrm{~nm}$ and the AEs derived from these three wavelengths. Therefore, part of the difference can be explained by the interpolation-related uncertainties. POM sky radiometers do not measure AOD at 368 and $412 \mathrm{~nm}$. However, comparable results to the CIM and PFR at $862 \mathrm{~nm}$ was retrieved, with a slight underestimation, well within the WMO limits, at $500 \mathrm{~nm}$ (Fig. 2b), which was not related to the air mass. These results demonstrate the high level of the quality of reference instruments belonging to the GAW-PFR, AERONET and SKYNET networks. The two SPOs, which are similar instruments to the PFRs but with a wider FoV and with no temperature controller, showed good agreement 

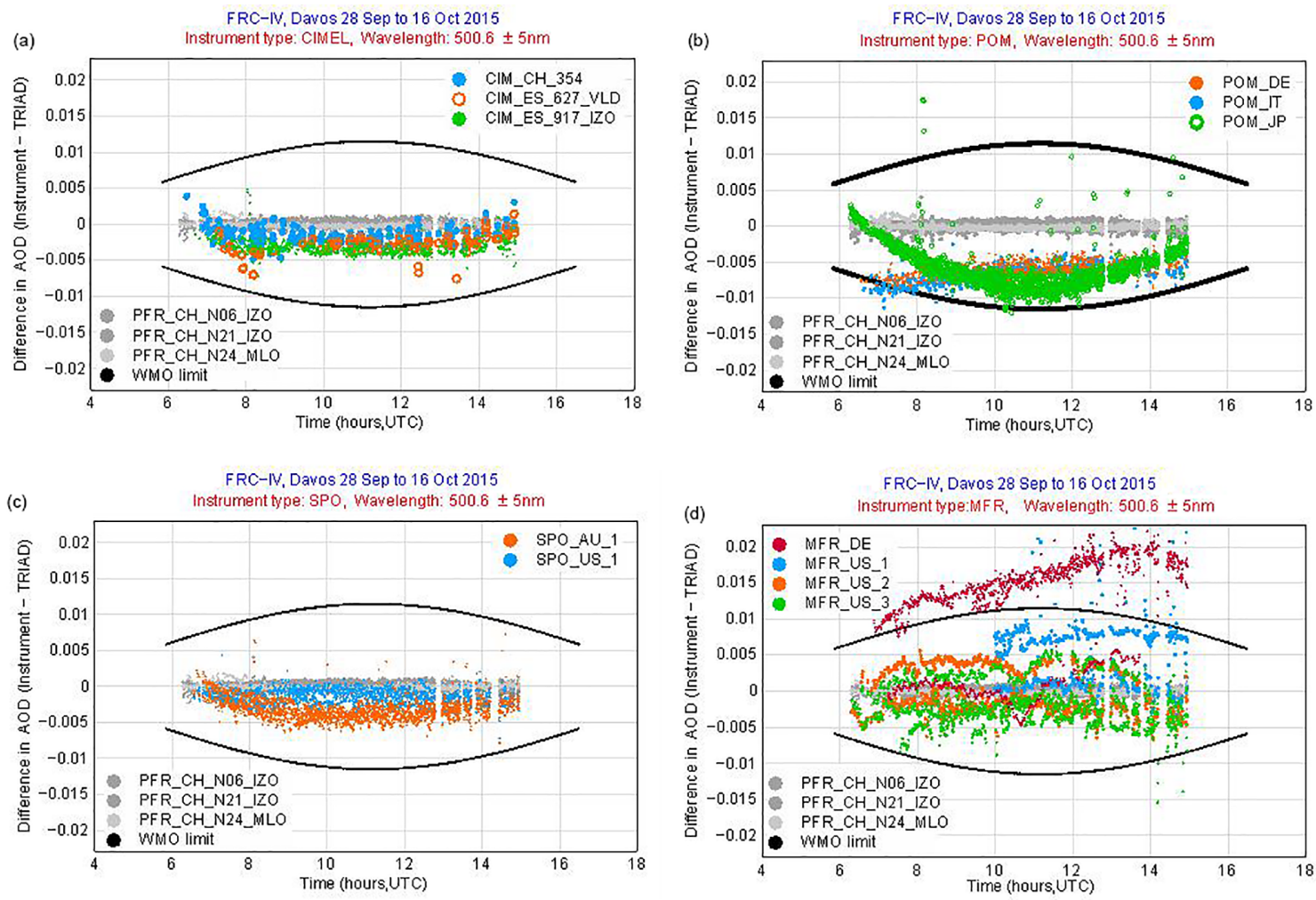

Figure 2. Comparison of the triad (gray points) with the Cimel instruments (a, $500 \pm 5 \mathrm{~nm}$ ), POM instruments (b, $500 \pm 5 \mathrm{~nm})$, SPO instruments $(\mathbf{c}, 500 \pm 5 \mathrm{~nm})$ and with the MFR instruments $(\mathbf{d}, 862 \pm 5 \mathrm{~nm})$. Different colors represent different instruments for all the five comparison days, and gray lines represent the WMO AOD limits.

compared to the triad. SPO_AU_1 showed excellent median differences (Fig. 2c). For the SPO_US_1, one of the 5 days of measurements at $500 \mathrm{~nm}$ and one of the 5 days at $862 \mathrm{~nm}$ gave overestimated values, with excellent agreement on other days and excellent agreement on all days at $500 \mathrm{~nm}$. The overestimates were likely the result of the four FoVs of the SPO not being optimally aligned. During the shipment of the SPO2_US_1 to Davos, the diopter was damaged. It was manually adjusted to its position during FRCIV without the benefit of a detailed alignment process that is usually conducted to minimize the misalignment of the four independent barrels of the sun photometer. At $368 \mathrm{~nm}$, small SPO_AU_1-calibration-related AOD differences were observed compared to the triad. The four multi-filter radiometer (MFR) instruments showed good agreement for the medians compared to the PFR triad; however, they exhibit larger scatter than the sun-pointing instruments, resulting in a lower precision. McArthur et al. (2003) had previously reported that the MFR-derived AOD does not quite meet the accuracy of the sun-pointing instruments under clean atmospheric conditions. MFR_DE showed an AOD overestimation in various instances that gave results that are outside the WMO-defined AOD limits (Fig. 2d). This small overestimation of the MFR_DE instrument compared to the PFR triad could be due to uncertainties introduced while correcting for their angular response, by the calibration procedure or by incomplete blocking of the diffuser by the shadow band. The MFRSRs that are part of the SURFRAD network (MFR_US2 and MFR_US3) gave a median AOD at $500 \mathrm{~nm}$ that is in very good agreement with the PFR triad and is in fact better than some of the other sun-pointing instruments, e.g., Cimel and POM; these two slightly underestimate the AOD at $865 \mathrm{~nm}$ but are within the WMO defined limits. Again, these median values of these two MFRs are comparable to the better sun-pointing instruments but give larger scatter. These two MFRs are representative of the SURFRAD network that follows network protocols for calibration and alignment and conducts frequent characterizations of the spectral and angular responses (Augustine et al., 2003; Michalsky et al., 2010). Again, this highlights the high level of the quality of instruments that represent larger networks (GAW-PFR, AERONET, SKYNET and SURFRAD networks).

Looking at possible diurnal patterns of the AOD differences shown in Fig. 2, most of the instruments show relatively constant differences over time (and air mass). One example of a possible diurnal pattern in the AOD differences that can be linked with the instrument calibration (as discussed in Cachorro et al., 2004) is the POM_JP instrument. In that study, differences are proportional to $1 / \mathrm{m}$ and are up to 0.01 for high air masses. In this case, if the calibration 


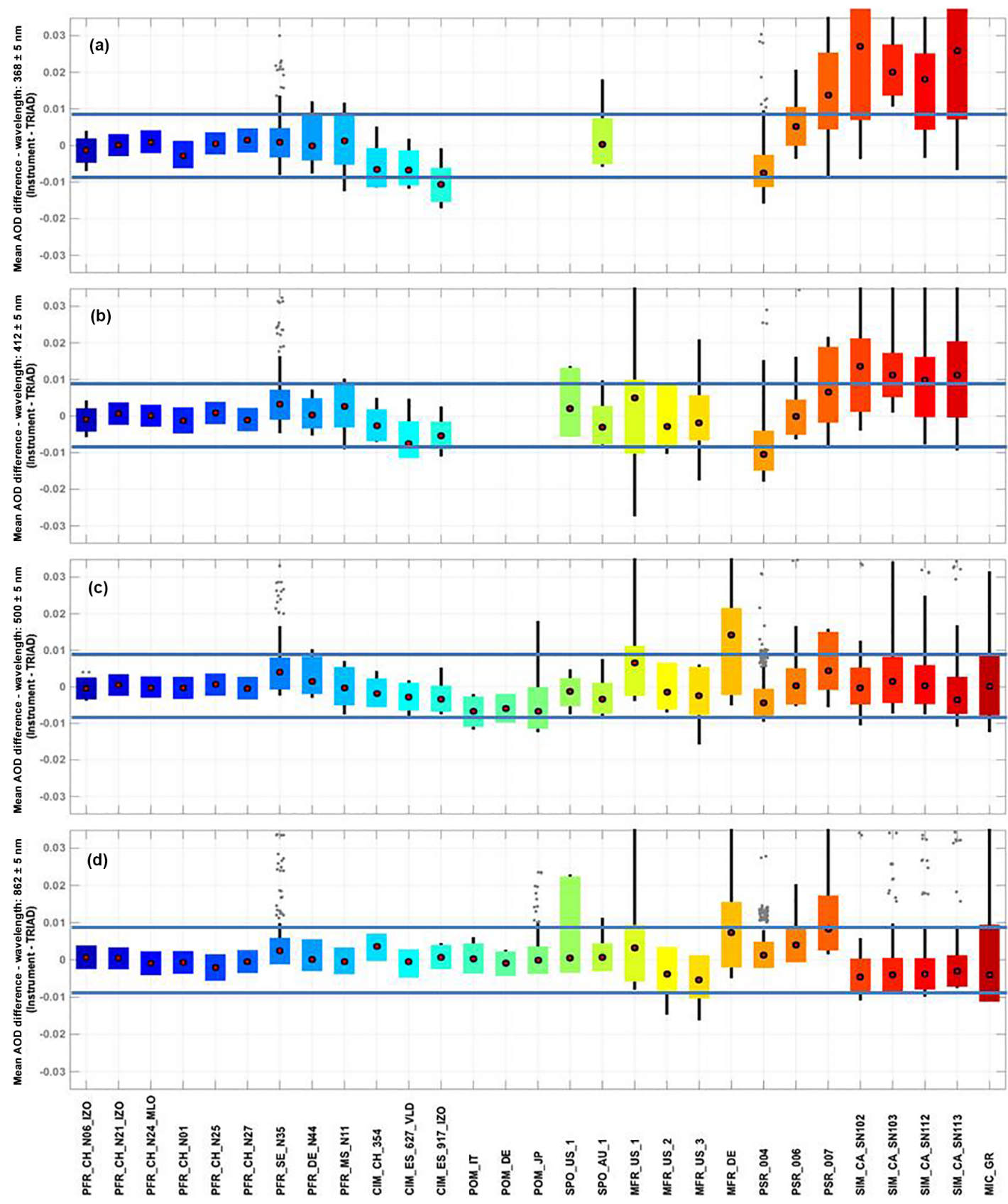

Figure 3. AOD comparison results at $368 \pm 3 \mathrm{~nm}$ (a), $412 \pm 3 \mathrm{~nm}$ (b), $500 \pm 3 \mathrm{~nm}$ (c) and $865 \pm 5 \mathrm{~nm}$ (d). The black dots represent the median of the difference of each instrument from the mean of the triad at each wavelength over the five FRC-IV selected days. The boxes represent the 10th and 90th percentiles, while the black lines represent the minimum and maximum values of the distribution excluding the outliers. Outliers (gray dots) represent values that are outside the 10th and 90th percentiles by 4 times the width of the distribution at a $10 \%$ level. Cimel AOD at 368 and $412 \mathrm{~nm}$ has been interpolated using the Cimel AOD at 340,380 and $440 \mathrm{~nm}$ and the Ångström exponents derived from these three wavelengths. Box colors are only used to differentiate between instruments. Blue lines represent the \pm 0.09 limits.

effect is isolated, the error of the instrument calibration (assuming the PFR triad calibration is ideal) is on the order of $1.6 \%$.

Figure 3 shows the comparison results in terms of absolute difference between the triad and the nine individual
PFR instruments, three CIM (AERONET) instruments, three POM (SKYNET) instruments, two SPOs, four MFRs, three PSRs, four SSIM instruments and one MIC instrument. The box plots represent the range between the 10th and 90th percentiles, with the in-box dot showing the median and the up- 


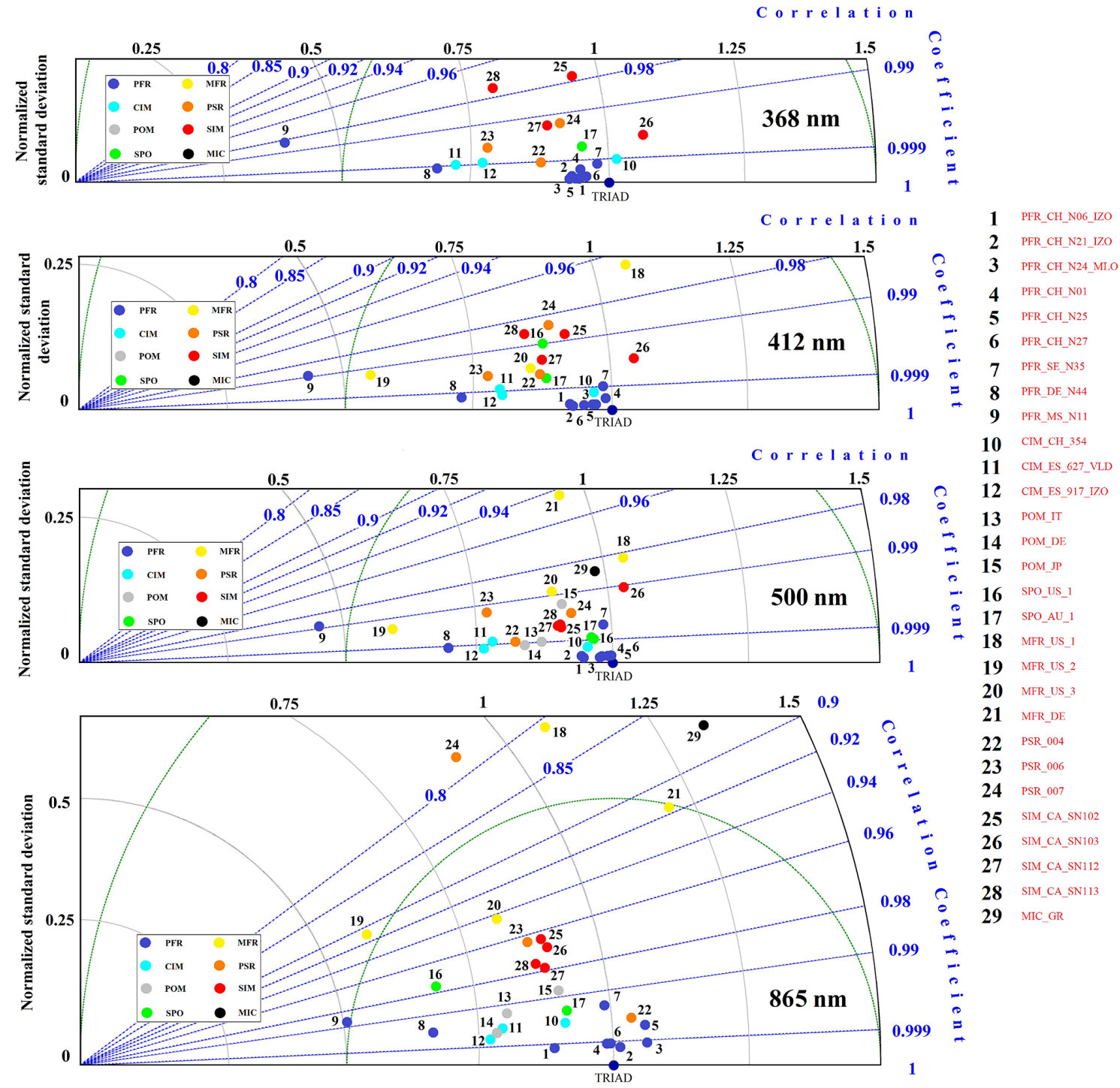

Figure 4. Taylor diagrams at the four measuring wavelengths.

per and lower whiskers showing the maximum and minimum error value information that is within 1.5 times the interquartile range of the box edges. The figure shows the good agreement among most of the instruments compared to the reference triad. WMO limits cannot be shown in Fig. 3 as they are air-mass-dependent. However, for FRC-IV these limits were between 0.006 and 0.012 for low solar elevations and local noon, respectively.

PFR AOD comparisons showed that median differences were well within \pm 0.005 , with the 10 th to 90 th percentiles also well within \pm 0.01 AOD limits, at all wavelengths. Similar results were found for Cimel AODs at 500 and $862 \mathrm{~nm}$. POM AOD medians showed a small underestimation of about 0.005 at $500 \mathrm{~nm}$ and very good agreement at $865 \mathrm{~nm}$. The medians of the MFRs AODs were within 0.01 AOD except for the MFR_DE_1 at $500 \mathrm{~nm}$. The three PSR in- struments are the only ones that provide high spectral resolution AOD measurements, and the comparisons highlighted the accuracy of the medians at longer wavelengths (500 and $862 \mathrm{~nm}$ ), with a tendency of overestimated outliers and a 0 to 0.02 discrepancy between the PSRs at shorter wavelengths. Overall, better results were demonstrated by PSR_006. SIM instruments showed an excellent agreement at 500 and $865 \mathrm{~nm}$, an overestimation from 0.01 to 0.03 and higher scatter than the other instruments. However, based on the instrument retrieval methodology (use of a radiative transfer model with direct irradiances as inputs in order to calculate AOD), the results can be considered to be very good. Finally, the handheld Microtops instrument overestimated at the two shorter wavelengths, while the scatter of the differences was 0.01 to 0.04 for the 10 th to 90 th percentiles. The blue lines in Fig. 3 are defined as the -0.09 and 0.09 
AOD limits. This is an average of the air-mass-related WMO limit that ranged from 0.06 to 0.12 for the campaign period. Cimel AOD at 368 and $412 \mathrm{~nm}$ has been interpolated using the Cimel AOD at 340, 380 and $440 \mathrm{~nm}$ and the Ångström exponents derived from these three wavelengths.

Overall, the FRC-IV intercomparison results are comparable with the results found by Mitchell and Forgan (2003), Mitchell et al. (2017) and Kim et al. (2008) under low aerosol loading conditions. The magnitude of the instrument's discrepancy could be partly due to the inherently different spectral responses and detector fields of view of each instrument under varying aerosol loadings (Kim et al., 2005). The above results indicate that the pointing instruments provide data of comparable quality. On an observation-by-observation basis, the direct-pointing instruments appear to maintain a difference of lower than 0.01 at nearly all wavelengths in clear stable conditions, equal to or lower than the AOD uncertainty. It is estimated that advances in the following aspects may improve (see Sect. 3.3) agreement at the 0.005 level: (i) instrument pointing, (ii) better determination of the effects of Rayleigh scattering, ozone and other absorbers on the calculation of AOD and (iii) better instrument characterization, especially calibration of the radiometers. Significant improvements in AOD precision and instrument accuracy were obtained upon application of cloud screening.

Concerning additional statistics, we have used Taylor diagrams (Taylor, 2001) in order to evaluate the performance of all instruments at the four measuring wavelengths (Fig. 4). Correlation coefficients (CCs) among the triad and all other instruments were better than 0.9 for all instruments and wavelengths, with the exception of three instruments, only at $865 \mathrm{~nm}$. In the case of the Cimel, PFR and POM, CCs were higher than 0.98 in all cases. The normalized standard deviation in Fig. 4 describes the instrument-measured AOD variability compared to that of the reference (triad). Most of these ratios were well within the 0.8 to 1 area, with the exception of a single PFR instrument, which provided data for only one comparison day.

Overall, statistics at 368, 412 and $500 \mathrm{~nm}$ showed an excellent agreement for all instruments, while at $865 \mathrm{~nm}$ the instrument scatter within the Taylor diagram space is higher. However, the agreement can still be considered quite good, as seen when examining Fig. 4.

Figure 5 presents the percentage of instruments that lie within the WMO AOD uncertainty criterion. The wavelengths with the lower percentage of instruments within the defined criterion are the nominal 368 and $412 \mathrm{~nm}$ channels, while the majority of instruments measure within the defined criterion for the nominal 500 and $865 \mathrm{~nm}$ channels (see Table 2). When considering $95 \%$ of measurements, the best results correspond to the $500 \mathrm{~nm}$ wavelength followed by the $867 \mathrm{~nm}$ wavelength. A main finding is that the lower the wavelength, the lower the reliability, accompanied by the lower percentage of participating/supporting instruments. For a lower percentage of measurements (horizontal axis)

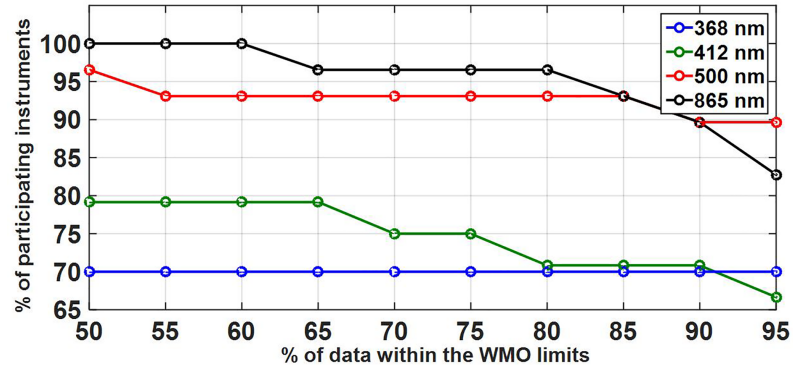

Figure 5. Percentage of instruments that lie within the WMO criterion $(0.005+0.01 / m$ optical depths $)$. The horizontal axis shows the different percentages of measurements within the criterion ending at $95 \%$, which is the U95 WMO limit.

the $865 \mathrm{~nm}$ wavelength reaches $100 \%$ of participating instruments, which decreases to $83 \%$ at $95 \%$ of data within the WMO limits. The shortest studied wavelength $(368 \mathrm{~nm})$ showed that 12 out of 17 instruments were within the WMO criterion, while the remaining five had less than $70 \%$ of the comparison data among the WMO limits.

The difference in the AE between all participant instruments and the triad is shown in Fig. 6. We have used only the $500 / 865 \mathrm{~nm}$ channels to calculate the AEs in order to have the same calculation principles for all instruments.

Under low aerosol conditions, a small relative bias in the AOD determination at 500 and $865 \mathrm{~nm}$ can theoretically lead to large deviations in the calculated AEs. As an example, for AODs of about 0.05 and 0.02 at 500 and $865 \mathrm{~nm}$, respectively, AOD differences of 0.01 and 0.005 , respectively, can lead to AE differences up to $\sim 1$. This was observed during FRC-IV, and Fig. 6 shows that for such low AOD conditions, AEs can differ substantially. Most of the AE instruments differ from the triad-calculated AE by less than 0.5 (median difference) but the 10th to 90th percentiles are about 0.5 for the PFRs and close to 1 for all other instruments, with the exception of the Microtops instrument retrievals that showed a very large variability in $\mathrm{AE}$ difference.

\subsection{Cloud flagging}

The FRC campaign was a unique opportunity to compare the different cloud-screening algorithms used by each instrument/group. McArthur et al. (2003) reported on instrument/network-related cloud-flagging differences using measurements from a 3-month campaign. The use of such algorithms can lead to significant differences, while the selection of threshold values to filter out the retrievals could lead to large deviations when comparing AOD retrievals from instruments with different cloud-flagging algorithms. For our comparison, we have used one of each of the main types of instruments and compared the number of available retrievals (PFR, POM, SPO, MFR and Cimel instruments). 


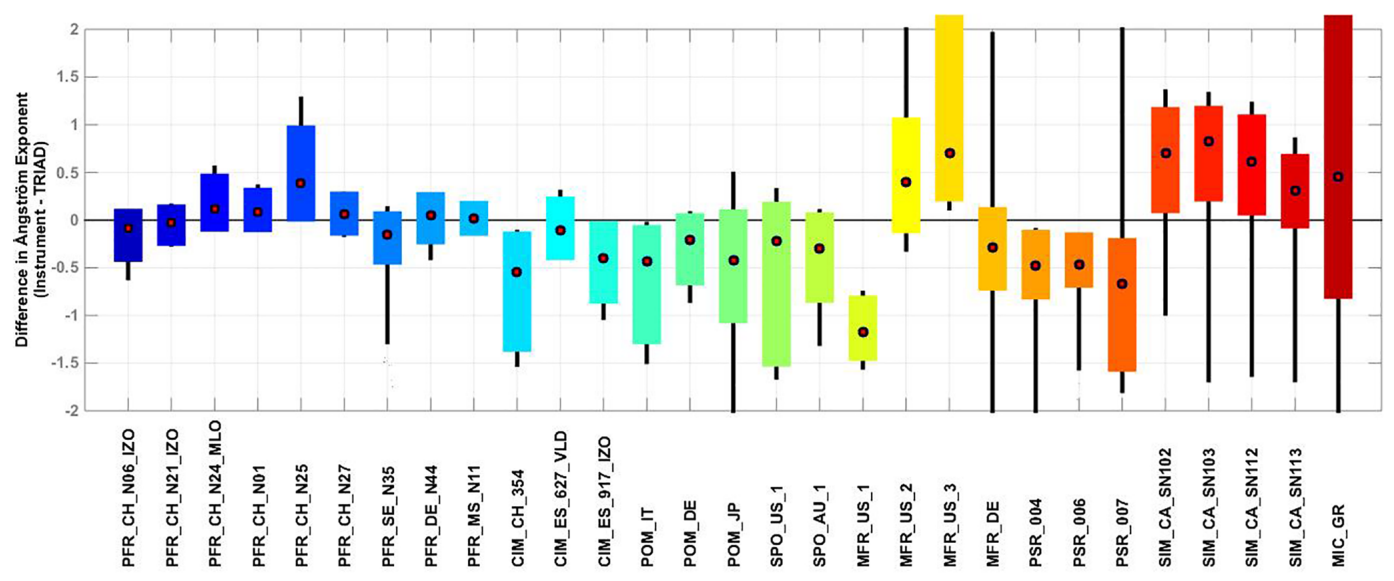

Figure 6. Difference in the Ångström exponent between each instrument and the WORCC triad. The boxes represent the 10th and 90th percentiles, while the black lines represent the minimum and maximum values of the distribution excluding the outliers. Outliers (gray dots) are considered to be values outside the 10th and 90th percentiles by 4 times the width of the distribution at a $10 \%$ level. Box colors are only used to differentiate between instruments.

More specifically, we have chosen to examine the instruments of each type with the larger dataset on these 5 days.

The cloud detection algorithm used for the abovementioned instruments can be summarized as follows.

Cimel. The AERONET operational cloud-screening algorithm, described by Smirnov et al. (2000, 2004), was used. It consists of temporal filtering in several steps, from minute (triplet stability, with AOD variation $<0.02$ ) to hour, and diurnal checks, which impose restrictions on the AOD second derivative with time as well as the standard deviation of AOD within the day.

PFR. Three different criteria are used (Wehrli, 2008). (a) The instrument signal derivative with respect to air mass is always negative (Harrison et al., 1994). For cases of air masses $<2$ where a cloud influence on the noon side of a perturbation cannot be easily detected, a comparison of the derivative with the estimate of the clear Rayleigh atmosphere is performed and data are flagged as cloudy if the rate of change is twice as much (objective method). (b) A test for optically "thick" clouds with AOD $>2$ is performed. (c) Tthe Smirnov et al. (2000) triplet measurement is used by calculating AOD and looking at the signal variability for three consecutive minutes (triplet method).

POM. The Smirnov et al. (2000) algorithm was implemented in the SUNRAD code which was used for the POM instruments (Estellés et al., 2012), with two main differences related to instrument characteristics. First, the minimum signal threshold is set to $5.0 \times 10^{-7} \mathrm{~A}$. Second, triplets are built a posteriori with $1 \mathrm{~min}$ instead of $30 \mathrm{~s}$ data, as used in the Cimel. A further check was introduced in the current version of the processing software, which is consistent in removing isolated AOD data points; namely, a given AOD point will be flagged if the previous and next AOD values were already flagged in the standard application of the cloud-screening algorithm.

SPO. The selection of valid AOD values for a sample time is made up of three components, with the first two related to measured signals and the last one based on the estimated AODs plus cloud/shade value. For each time sample, if the $868 \mathrm{~nm}(10 \mathrm{~nm}$ FWHM) signal was below a standard threshold, all wavelength channels are cloud-flagged or not oriented to the sun. Secondly, if the maximum signal of all wavelength signals for a sample time was less than 10 times the resolution of the data acquisition system, all wavelength signals for the sample time are flagged as being cloudy or shaded. Lastly, for each wavelength and for all remaining signals, the AOD is derived and the Alexandrov et al. (2004) algorithm with a time span of 15 sequential samples is used to examine each wavelength's AOD time series; if AOD at any wavelength is rejected by the algorithm for a sample time, the AOD is deemed to be affected by clouds at all wavelengths.

$M F R$. The technique used for MFRs is described in Michalsky et al. (2010). A coarse filter is used on $10 \mathrm{~min}$ of data; this examines differences first from the $20 \mathrm{~s} \mathrm{sam}$ ple to the $20 \mathrm{~s}$ sample and then over the entire $10 \mathrm{~min}$ interval. This is followed by a second similar filter but using allowance of variability that is scaled to the approximate value of the AOD. If the $10 \mathrm{~min}$ span passes both tests, the test is repeated after advancing one $20 \mathrm{~s}$ sample. Duplicate points from processing all of the data are discarded.

We have used the tool developed by Heberle et al. (2015) to visualize the coincidence of the instrument datasets that provided 1 min AOD (SPO, MFR, PFR and POM) by plotting Venn diagrams (Fig. 7). Cimel instruments were not included due to the lower AOD-measuring temporal resolution. All instruments only detected cloudless conditions during $25 \%$ of the common measurements. The SPO seems to have 
Table 3. Percentage of available cloud-screened AOD data values out of all possible measurements (minutes).

\begin{tabular}{lr}
\hline Instrument type & Score $\%$ \\
\hline PFR & 88.4 \\
POM & 39.7 \\
SPO & 89.1 \\
MFR & 70.9 \\
Cimel & $82.1^{*}$ \\
\hline
\end{tabular}

* Taking into account the Cimel measurement frequency.

the most values that do not appear in common with other instruments $(4.9 \%$ solo, and $18 \%$ in common with only one other instrument) and the POM the least $(0.1$ and $0.8 \%)$. When considering measurements defined as cloudless from at least three out of four instruments, the SPO has the largest number of coincident measurements $(69.9 \%)$ followed by the PFR $(69.2 \%)$, MFR $(59.9 \%)$ and POM (36.3\%). The POM has the smallest dataset, only retrieving AOD from $40 \%$ of all possible (at least one instrument provided cloudless AODs) measurements.

In order to investigate measurements when only one instrument provides cloud-free minute measurements while all other instruments are marked as cloud-flagged (as an example in Fig. 7, the SPO has 96 cases/minutes out of a possible 1944 comparison data/minutes), we calculated an artificial AOD time series. This was constructed by splineinterpolating the mean AOD of all the remaining (three) instruments (excluding the Cimel that has a lower temporal measurement frequency than the rest of the instruments), at the time intervals for which the fourth instrument (SPO in this example) provides cloud-free data. It was found that the mean $\mathrm{AOD}$ at $500 \mathrm{~nm}\left(\mathrm{AOD}_{500}\right)$ and the $\mathrm{SPO}$ retrieval difference is $20.5 \%$. In this example, on the one hand a $20.5 \%$ increase of AOD over one or a few minutes could be considered as a reason for rejection (cloud flagging) for all other algorithms, except that of the SPO. However, a difference of 0.006 in optical depth could be considered as a limit on trying to separate aerosol and very thin cloud attenuation.

In Table 3, we have calculated the score for each instrument, dividing the number of available retrievals by a total of 1944 possible (at least one of the instruments has provided an AOD cloud-free minute value) comparison cases. For Cimel values, for which the measurements are not every minute, we used raw data to count all the recordings and divide the number of cloud-screened data; therefore it is not directly comparable with other instruments. The POM instruments obtained the lowest score in the cloud-screening application, mainly caused by the stringent isolation check added to the adapted Smirnov et al. (2004) algorithm.

Figure 8 shows AOD measurements at $500 \mathrm{~nm}$ for all instruments that were tested for their cloud-flagging algorithms during one single day. As seen in Table 3, the POM in- strument seems to cloud-flag various minutes/measurements, while all other instruments/algorithms do not. Such instances are shown in Fig. 8 as gray areas and represent periods when all PFR, SPO and MFR instruments provide AOD (thus they do not "detect" any clouds) while the POM does not provide an AOD. Despite the small instrument-to-instrument differences, the evolution of the AOD during particular periods (gray areas), also described by the mean or artificial AOD, cannot be considered as periods that are affected by clouds. Thus, the POM algorithm is probably too strict compared to the others. In addition, sporadic SPO-related high AOD values after 14:00 UT (at times when no other instrument provides cloudless data) show that during these conditions, the SPO cloud-flagging algorithm was more imprecise.

\subsection{AOD retrieval differences}

For the present intercomparison, no common procedures were used for the removal of gas-phase constituents or Rayleigh scattering; cloud screening, solar position, timing and calibration methodology were at the discretion of the network operators. Datasets from each sun photometer network were corrected for these factors independently. Figure 9 identifies some of the possible discrepancies that may result when considering $\mathrm{NO}_{2}$, ozone, Rayleigh scattering, other trace gases and $\mathrm{H}_{2} \mathrm{O}$ in the atmosphere (Thome et al., 1992) at 500 and $870 \mathrm{~nm}$ during FRC-IV.

One reference day (30 September 2015) was chosen for this comparison exercise. The slant optical thicknesses of various trace gases and Rayleigh scattering were obtained from Cimel, PFR, POM and SPO instruments and individually compared. Furthermore, the respective algorithms for the calculation of the solar zenith angle and air mass at any given time (as provided by the responsible scientists of each instrument) were employed. $\mathrm{NO}_{2}$ absorption was considered only for POM (fixed vertical column density of $0.218 \mathrm{DU}$ for midlatitude summer; method and cross sections from Gueymard, 1995, 2001) and Cimel instruments (SCIAMACHY monthly climatology; cross sections from Burrows et al., 1998) and only for AOD retrieval at $500 \mathrm{~nm}$ wavelength. Ozone absorption was taken into account by all instruments at $500 \mathrm{~nm}$ but was not accounted for by the Cimel at $870 \mathrm{~nm}$. Different ozone amounts (measured value of 314 DU for PFR and SPO; fixed value of 300 DU for POM; Ozone Monitoring Instrument (OMI) climatology for Cimel) and cross sections (Gueymard, 1995, for PFR; Gueymard, 1995, 2001, for POM; Burrows et al., 1999, for Cimel; custom set of ozone coefficients for SPO) were adopted. The Rayleigh scattering coefficients by Bodhaine et al. (1999) are used by all networks except SPO, which used those by Bucholtz (1995). Pressure was measured $(845.7 \mathrm{hPa})$ by the PFR control box, while it was fixed and corrected for altitude $(z)$ for the POM $(840 \mathrm{hPa})$ using the following formula: 
(a)

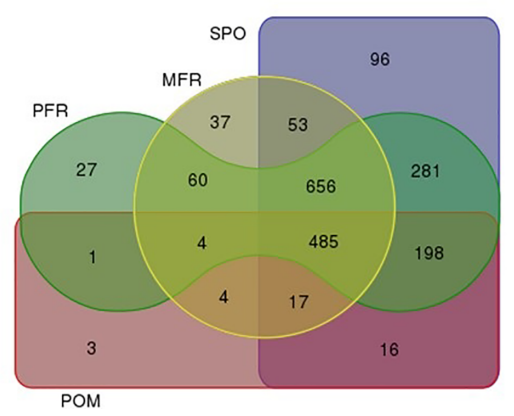

(b)

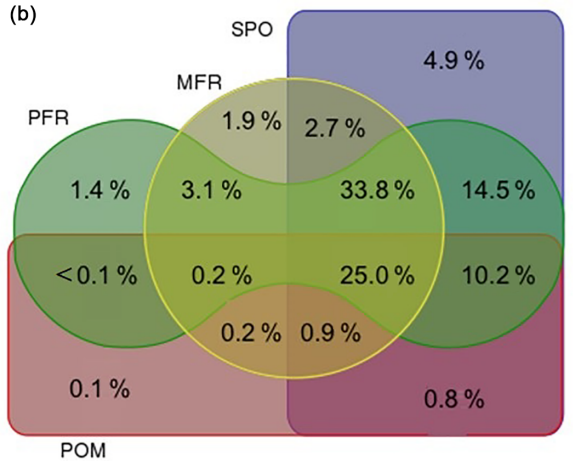

Figure 7. Venn diagram of quality-controlled, clear-sky datasets of SPO, MFR, PFR and POM data for four cloudless (only very limited presence of clouds) days. (a) Number of measurements, (b) percentage of measurements.

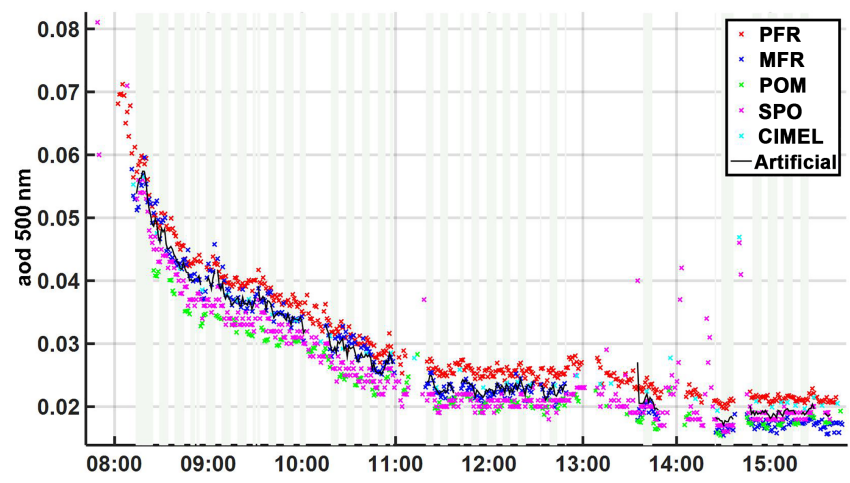

Figure 8. One-minute AOD data on 1 October 2015. Different colors represent the AODs, submitted as cloud-free data. The black line is the mean AOD from the PFR, MFR and SPO for data points when all three instruments provided data. The gray vertical lines represent periods where the PFR, MFR and SPO provided data but the POM characterized them as "cloudy".

$p=1013.25 \cdot \exp (-0.0001184 \cdot z)(1)$.

Finally, water vapor is only taken into account by POM instruments using a fixed value for the summer season and additionally corrected for altitude using the following formula based on data in Gueymard (1995):

$w=2.9816 \cdot \exp (-0.552 \cdot z)$

where $w$ is the precipitable water in centimeters and $z$ is the altitude in kilometers. The method for deriving the corresponding $\mathrm{H}_{2} \mathrm{O}$ optical depth is also adopted from Gueymard (2001). Results of this comparison exercise are shown in Fig. 9.

The analyzed factors result in discrepancies of comparable magnitude at a wavelength of $500 \mathrm{~nm}$ but also illustrate a slightly larger effect due to differences in the corrections for Rayleigh scattering and water vapor. At $870 \mathrm{~nm}$, the larger discrepancies can be ascribed to different parametrizations of ozone absorption and Rayleigh scattering. For the case of the MFR instrument, the effective wavelength of the "500 nm" filter is about $495.8 \mathrm{~nm}$, which explains the higher Rayleigh optical thickness and the lower ozone absorptionrelated value. The deviations between algorithms can be of either sign and can partially compensate each other in AOD calculations. Finally, $\mathrm{NO}_{2}$-related differences were 0.002 to 0.004 at $500 \mathrm{~nm}$, at a location (Davos) with very low $\mathrm{NO}_{2}$ columnar concentrations. The error in the (vertical) AOD resulting from differences between the algorithms (obtained by dividing the differences in the slant optical thicknesses by the air mass factor) did not exceed 0.005 for the selected day. This value is far below the traceability threshold and can thus be considered negligible.

\section{Summary and conclusions}

Results from the FRC-IV intercomparison have been presented in this study. Based on the number of instruments and also the participation of reference sun photometers/instruments from various global AOD networks, the campaign could be considered as a successful experiment in assessing the current status of AOD measurement accuracy and precision. The WMO recommendations for AOD comparisons have been adopted for the present campaign and the WORCC PFR triad has been used as a reference.

The absolute differences of all instruments compared to the reference triad have been reported and are based on the WMO criterion defined as follows: "95\% of the measured data has to be within $0.005 \pm 0.001 / \mathrm{m}$ ". At least 24 out of 29 instruments achieved this goal at 500 and $865 \mathrm{~nm}$, while 12 out of 17 and 13 out of 21 achieved this at 368 and $412 \mathrm{~nm}$, respectively.

The statistics from the Taylor diagram analysis revealed the overall accuracy and homogeneity of the instruments. In particular, the majority of instruments gave CCs $>0.98$ and a normalized standard deviation in the range $0.75-1$ as com- 

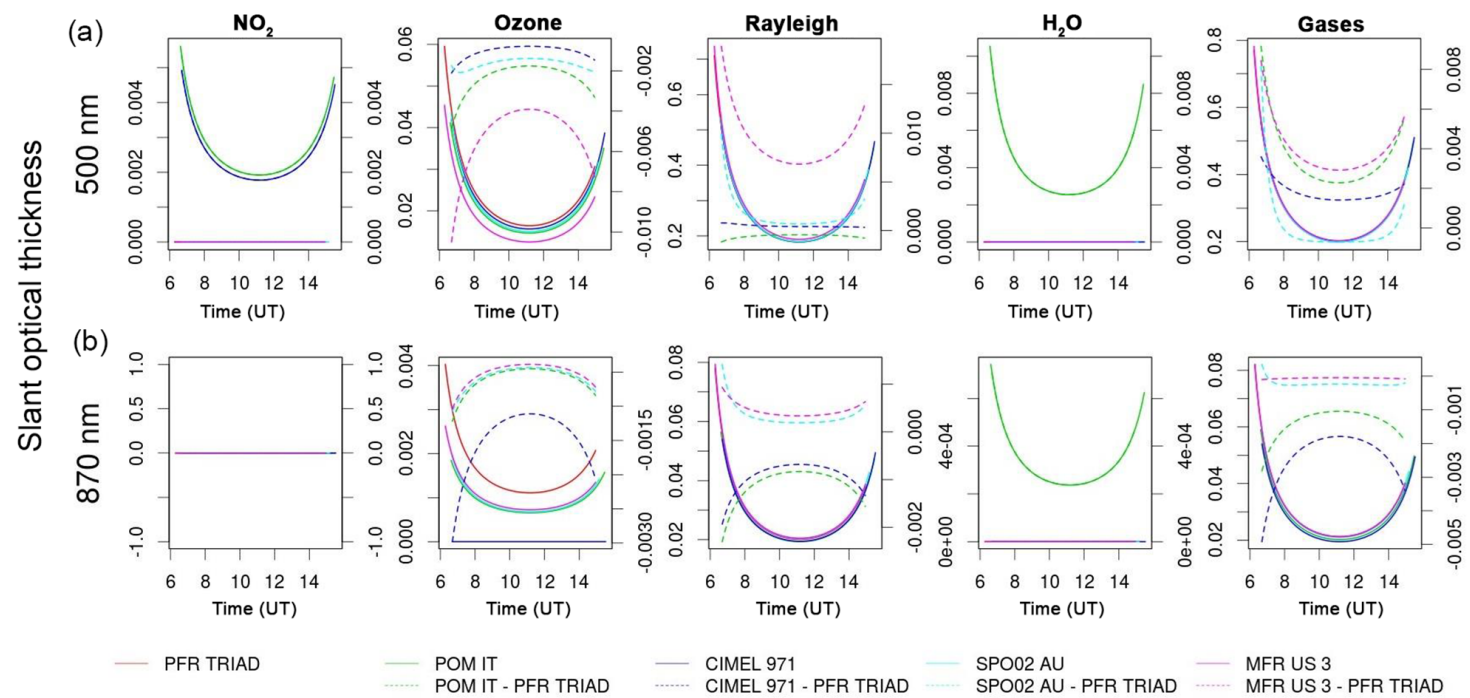

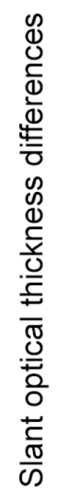

Figure 9. Slant column optical thickness (right axis - thick lines) and optical depth differences compared with the triad (left axis dashed lines), at 500 (a) and $870 \mathrm{~nm}$ (b).

pared to the triad, at all wavelengths. The similarity of results and the high accuracy of the PFR, CIM and POM instruments demonstrate a promising framework to achieve network homogeneity in the near future, concerning the AOD measurements. The PSR spectroradiometers and SIM and SPO filter radiometers also had CCs over 0.96 under all conditions.

Ångström exponent calculations using a pair (500 nm and $865 \mathrm{~nm}$ ) of wavelengths showed relatively large differences among different instruments. This was largely related to the uncertainty of this parameter that is linked with very low AOD uncertainties, under low AOD conditions. AOD differences of about 0.01 at $500 \mathrm{~nm}$ that can be easily related to the instrument calibration uncertainties can considerably affect such calculations during low AOD conditions. Hence, this campaign reaffirms that for cases of mean $\mathrm{AOD}_{500}<0.1$, the calculation of $\mathrm{AE}$ becomes highly uncertain.

Investigating the sources of differences among different instruments, we compared all parameters included in the AOD retrieval algorithm as provided by the different participating institutes. All individual differences (Rayleigh, $\mathrm{NO}_{2}$, ozone, water-vapor-related optical depths and air mass calculations) amounted to less than 0.01 in AOD at 500 and $865 \mathrm{~nm}$.

Different cloud-flagging algorithms can affect the AOD datasets as different instruments/networks use different techniques. During a day with sporadic appearances of high and mid-level clouds (which was deliberately chosen as a "difficult" task for such algorithms), results from different cloudflagging algorithms limited the AOD comparison datasets between two instruments from 40 to $90 \%$, depending on the pair of instruments used, compared to the maximum number of cloudless data points calculated by all instruments. In general, using long-term series for determining aerosol climatol- ogy at certain locations, cloud screening that is too conservative could lead to the elimination of high AOD local events, while too much conservative cloud screening will introduce biases linked mainly with cirrus clouds. Both approaches will have an impact on aerosol climatology and calculated AOD trends.

In comparison to earlier FRCs (I to III), the latest FRC reported here experienced an increase in both the number of instruments (total of 30) and international participating institutes (12 countries). In addition, analysis at four different wavelengths was performed for the first time. The Cimel/AERONET, PFR/GAW and POM/SKYNET and SPO participating sun photometers showed very good agreement when compared to older intercomparisons. As AOD from algorithm differences was quite small, the results of the comparisons of this instrument group are considered to have been very successful as differences are in most cases well within the calibration and overall instrument AOD uncertainties. The rest of the instruments also showed reasonable agreement with few exceptions. MFR instruments experienced additional uncertainties concerning the diffuser-based measurements. SIM instruments also performed quite well when considering the radiative-transfer-based processing algorithm. In addition, spectral-AOD-retrieving PSR instruments also performed well, especially at the two higher wavelengths. Finally, Microtops AOD data were in most cases within reasonable agreement with the reference triad but additional technical issues such as the handheld-based sun-pointing and the smaller integration time (compared with other instruments) of the direct sun measurement led to enhanced scatter of the results.

Instrument technical features such as differences in the field of view did not play an important role in FRC-IV for the 
low aerosol load conditions that were encountered. In order to quantify such features and similar issues, intercomparison campaigns have to be organized in moderate to high AOD conditions when forward scattered radiation and circumsolar radiation can play an important role in instruments with different field-of-view entrance optics.

The results of the FRC-IV, which included a large variety of AOD measuring instrumentation via the participation of reference instruments from AERONET Europe, SKYNET, GAW-PFR, SURFRAD and the Australian Aerosol Network, could be considered as a starting point for global AOD harmonization of procedures, recommendations for cloud screening, trace gas corrections and calibration procedures. The ultimate objective is a unified AOD product to be used for long-term aerosol and radiative forcing studies, case studies involving accurate AOD retrievals and satellitevalidation-related activities.

Data availability. Reference triad aerosol optical depth measurements can be provided from PMOD/WRC upon request. Additional instrument data can be requested from the individual instrument principle operators.

\section{The Supplement related to this article is available online at https://doi.org/10.5194/acp-18-3185-2018-supplement.}

Competing interests. The authors declare that they have no conflict of interest.

Acknowledgements. FRC-IV was organized in the frame of the World Radiation Center-WORCC mandate for the homogenization and harmonization of AOD measurements as defined by WMOGAW. Authors would like to thank Christian Thomann for his essential and continuous technical support during the FRC-IV campaign.

Edited by: Evangelos Gerasopoulos

Reviewed by: three anonymous referees

\section{References}

Alexandrov, M. D., Marshak, A., Cairns, B., Lacis, A. A., and Carlson, B. E.: Automated cloud screening algorithm for MFRSR data, Geophys. Res. Lett., 31, L04118, https://doi.org/10.1029/2003GL019105, 2004.

Aoki, K., Hayasaka, T., Takemura, T., Nakajima, T., Kim, S. W., and Sohn, B. J.: Aerosol Optical Characteristics Measured by Sky Radiometers During the ABC/EAREX2005 Observation, KoreaJapan-China Joint Conference on Meteorology, Kintex Conference Center, 1-13 October, Goyang, Korea, 2006.
Augustine, J. A., DeLuisi, J., and Long, C. N.: SURFRAD - a national surface radiation budget network for atmospheric research, B. Am. Meteorol. Soc., 81, 2341-2357, 2000.

Augustine, J. A., Cornwall, C., Hodges, G., Long, C. N., Medina, C., and DeLuisi, J. J.: An automated method of MFRSR calibration for aerosol optical depth analysis with application to an Asian dust outbreak over the U.S., J. Appl. Meteorol., 4226642277, 2003.

Augustine, J. A., Hodges, G. B., Dutton, E. G., Michalsky, J. J., and Cornwall, C. R.: An aerosol optical depth climatology for NOAA's national surface radiation budget network (SURFRAD), J. Geophys. Res., 113, D11204, https://doi.org/10.1029/2007JD009504, 2008.

Barreto, Á., Cuevas, E., Granados-Muñoz, M.-J., AladosArboledas, L., Romero, P. M., Gröbner, J., Kouremeti, N., Almansa, A. F., Stone, T., Toledano, C., Román, R., Sorokin, M., Holben, B., Canini, M., and Yela, M.: The new sun-skylunar Cimel CE318-T multiband photometer - a comprehensive performance evaluation, Atmos. Meas. Tech., 9, 631-654, https://doi.org/10.5194/amt-9-631-2016, 2016.

Bodhaine, B. A., Wood, N. B., Dutton, E. G., and Slusser, J. R.: On Rayleigh Optical Depth Calculations, J. Atmos. Ocean. Tech., 16, 1854-1861, 1999.

Bucholtz, A.: Rayleigh-scattering calculations for the terrestrial atmosphere, Appl. Optics, 34, 2765-2773, https://doi.org/10.1364/AO.34.002765, 1995.

Burrows, J. P., Dehn, A., Deters, B., Himmelmann, S., Richter, A., Voigt, S., and Orphal, J.: Atmospheric Remote-Sensing Reference Data from GOME: Part 1. Temperature-Dependent Absorption Cross-Sections of $\mathrm{NO}_{2}$ in the 231-794 nm range, J. Quant. Spectrosc. Ra., 60, 1025-1031, 1998.

Burrows, J. P., Richter, A., Dehn, A., Deters, B., Himmelmann, S., Voigt, S., and Orphal, J.: Atmospheric Remote-Sensing Reference Data from GOME: Part 2. Temperature-Dependent Absorption Cross Sections of $\mathrm{O}_{3}$ in the 231-794 nm range, J. Quant. Spectrosc. Ra., 61, 509-517, 1999.

Cachorro, V. E., Romero, P. M., Toledano, C., Cuevas, E., and de Frutos, A. M.: The fictitious diurnal cycle of aerosol optical depth: A new approach for "in situ" calibration and correction of AOD data series, Geophys. Res. Lett., 31, L12106, https://doi.org/10.1029/2004GL019651, 2004.

Campanelli, M., Nakajima, T., and Olivieri, B.: Determination of the solar calibration constant for a sun-sky radiometer, Appl. Optics, 43, 651-659, https://doi.org/10.1364/AO.43.000651, 2004.

Campanelli, M., Estellés, V., Tomasi, C., Nakajima, T., Malvestuto, V., and Martínez-Lozano, J. A.: Application of the SKYRAD improved Langley plot method for the in situ calibration of CIMEL Sun-sky photometers, Appl. Optics, 46, 2688-2702, 2007.

Chylek, P., Henderson, B., and Mishchenko, M.: Aerosol radiative forcing and the accuracy of satellite aerosol optical depth retrieval, J. Geophys. Res., 108, 4764, https://doi.org/10.1029/2003JD004044, 2003.

Dirmhirn, I., Sreedharan, C. R., and Venugopal, G.: Spectral ultraviolet radiation instrument and preliminary measurements in mountainous terrain, Theor. Appl. Climatol., 46, 219-228, 1993.

Dutton, E. G., Reddy, P., Ryan, S., and DeLuisi, J.: Features and Effects of Aerosol Optical Depth Observed at Mauna Loa, Hawaii: 1982-1992, J. Geophys. Res., 99, 829-836, 1994. 
Estellés, V., Campanelli, M., Smyth, T. J., Utrillas, M. P., and Martínez-Lozano, J. A.: Evaluation of the new ESR network software for the retrieval of direct sun products from CIMEL CE318 and PREDE POM01 sun-sky radiometers, Atmos. Chem. Phys., 12, 11619-11630, https://doi.org/10.5194/acp-12-116192012, 2012.

Gueymard, C. A.: SMARTS2, A simple model of the atmospheric radiative transfer of sunshine: Algorithms and performance assessment, Florida Solar Energy Center/University of Central Florida, FSEC-PF-270-95, December 1995.

Gueymard, C. A.: Parameterized transmittance model for direct beam and circumsolar spectral irradiance, Sol. Energy, 71, 325346, 2001.

Harrison, L., Michalsky, J., and Berndt, J.: Automated Multi-Filter Rotating Shadowband Radiometer: An Instrument for Optical Depth and Radiation Measurements, Appl. Optics, 33, 51185125, 1994.

Harrison, L., Beauharnois, M., Berndt, J., Kiedron, P., Michalsky, J., and Min, Q.: The Rotating Shadowband Spectroradiometer (RSS) at SGP, Geophys. Res. Lett., 26, 1715-1718, 1999.

Heberle, H., Meirelles, G. V., da Silva, F. R., Telles, G. P., and Minghim, R.: InteractiVenn: a web-based tool for the analysis of sets through Venn diagrams, BMC Bioinformatics, 16, 1-7, https://doi.org/10.1186/s12859-015-0611-3, 2015.

Holben, B. N., Ech, T. F., Slutsker, I., Tanre, D., Buis, J. P., Setser, A., and Smironv, A.: AERONET: A Federated Insrument Network and Data Archive for Aerosol Characterization, Remote Sens. Environ., 66, 1-16, 1998.

Holben, B. N., Tanre, D., Smirnov, A., Eck, T. F., Slutsker, I., and Zibordi, G.: An emerging ground-based aerosol climatology: Aerosol optical depth from AERONET, J. Geophys. Res., 106, 12067-12097, 2001.

Kahn, R. A., Gaitley, B. J., Martonchik, J. V., Diner, D. J., Crean, K. A., and Holben, B.: Multiangle Imaging Spectroradiometer (MISR) global aerosol optical depth validation based on 2 years of coincident Aerosol Robotic Network (AERONET) observations, J. Geophys. Res., 110, D10S04, https://doi.org/10.1029/2004JD004706, 2005.

Kazadzis, S., Kouremeti, N., Nyeki, S., Gröbner, J., and Wehrli, C.: The World Optical Depth Research and Calibration Center (WORCC) quality assurance and quality control of GAW-PFR AOD measurements, Geosci. Instrum. Method. Data Syst., 7, 3953, https://doi.org/10.5194/gi-7-39-2018, 2018.

Kim, S. W., Jefferson, A., Yoon, S. C., Dutton, E. G., Ogren, J. A., Valero, F. P. J., Kim, J., and Holben, B. N.: Comparisons of Aerosol Optical Depth and Surface Shortwave Irradiance and Their Effect on the Aerosol Surface Radiative Forcing Estimation, J. Geophys. Res., 110, D07204, https://doi.org/10.1029/2004JD004989, 2005.

Kim, S. W., Yoon, S. C., Dutton, E. G., Kim, J., Wehrli, C., and Holben, B. N.: Global surface-based Sun photometer network for long-term observations of column aerosol optical properties: Intercomparison of AOD, Aerosol Sci. Tech., 1, 1-9, https://doi.org/10.1080/02786820701699743, 2008.

Levy, R. C., Mattoo, S., Munchak, L. A., Remer, L. A., Sayer, A. M., Patadia, F., and Hsu, N. C.: The Collection 6 MODIS aerosol products over land and ocean, Atmos. Meas. Tech., 6, 29893034, https://doi.org/10.5194/amt-6-2989-2013, 2013.
Li, J., Carlson, B. E., Dubovik, O., and Lacis, A. A.: Recent trends in aerosol optical properties derived from AERONET measurements, Atmos. Chem. Phys., 14, 1227112289, https://doi.org/10.5194/acp-14-12271-2014, 2014.

Lohmann, U. and Feichter, J.: Global indirect aerosol effects: a review, Atmos. Chem. Phys., 5, 715-737, https://doi.org/10.5194/acp-5-715-2005, 2005.

McArthur, B., Halliwell, D. H., Neibergall, O. J., O’Neill, N. T., Slusser, J. R., and Wehrli, C.: Field comparison of Network Sunphotometers, J. Geophys. Res., 108, 4596, https://doi.org/10.1029/2002JD002964, 2003.

Michalsky, J., Denn, F., Flynn, C., Hodges, G., Kiedron, P., Koontz, A., Schlemmer, J., and Schwartz, S. E.: Climatology of aerosol optical depth in north-central Oklahoma: 1992-2008, J. Geophys. Res., 115, D07203, https://doi.org/10.1029/2009JD012197, 2010.

Mitchell, R. M. and Forgan, B. W.: Aerosol measurement in the Australian outback: Intercomparison of Sun photometers, J. Atmos. Ocean. Tech., 20, 54-66, 2003.

Mitchell, R. M., Forgan, B. W., and Campbell, S. K.: The Climatology of Australian Aerosol, Atmos. Chem. Phys., 17, 5131-5154, https://doi.org/10.5194/acp-17-5131-2017, 2017.

Nakajima, T., Tonna, G., Rao, R., Boi, P., Kaufman, Y., and Holben, B.: Use of sky brightness measurements from ground for remote sensing of particulate polydispersions, Appl. Optica, 35, 2672 2686, 1996.

Nyeki, S., Halios, C. H., Baum, W., Eleftheriadis, K., Flentje, H., Grobner, J., Vuilleumier, L., and Wehrli, C.: Ground-based aerosol optical depth trends at three high-altitude sites in Switzerland and southern Germany from 1995 to 2010, J. Geophys. Res., 117, D18202, https://doi.org/10.1029/2012JD017493, 2012.

Sayer, A. M., Hsu, N. C., Bettenhausen, C., Jeong, M.-J., Holben, B. N., and Zhang, J.: Global and regional evaluation of over-land spectral aerosol optical depth retrievals from SeaWiFS, Atmos. Meas. Tech., 5, 1761-1778, https://doi.org/10.5194/amt-5-17612012, 2012.

Schmid, B. and Wehrli, C.: Comparison of sunphotometer calibration by use of the Langley technique and the standard lamp, Appl. Optics, 34, 4500-4512, 1995.

Schmid, B., Michalsky, J., Halthore, R., Beauharnois, M., Harrison, L., and Smirnov, A.: Comparison of Aerosol Optical Depth from Four Solar Radiometers During the Fall 1997 ARM Intensive Observation Period, Geophys. Res. Lett., 26, 2725-2728, 1999.

Shaw, G. E.: Error analysis of multi-wavelength sun photometry, Pure Appl. Geophys., 114, 1-14, 1976.

Shaw, G. E., Reagan, J. A., and Herman, B. M.: Investigations of Atmospheric Extinction using direct solar radiation measurements made with a multiple wavelength radiometer, J. Appl. Meteorol., 12, 374-380, 1973.

Smirnov, A., Holben, B. N., Eck, T. F., Dubovik, O., and Slutsker, I.: Cloud Screening and quality control algorithms for the AERONET database, Remote Sens. Environ., 73, 337-349, 2000.

Smirnov, A., Holben, B. N., Lyapustin, A., Slutsker, I., and Eck, T. F.: AERONET processing algorithms refinement, AERONET Workshop, 10-14 May, El Arenosillo, Spain, 2004.

Tatsiankou, V., Hinzer, K., Muron, A., Mohammed, J., Wilkins, M., Haysom, J., Schriemer, H., and Myrskog, S.: Reconstruction of the solar spectral resource using limited spectral sampling for 
concentrating photovoltaic systems, in: Photonics North 2013 Conference, 3-5 June 2013, Ottawa Convention Centre Ottawa, Canada, 2013.

Taylor, K. E.: Summarizing multiple aspects of model performance in a single diagram, J. Geophys. Res., 106, 7183-7192, 2001.

Thome, K. J., Herman, B. M., and Reagan, J. A.: Determination of precipitable water from solar transmission, J. Appl. Meteor., 31, 157-165, 1992.

Toledano, C., Cachorro, V., Gausa, M., Stebel, K., Aaltonen, V., Berjon, A., Ortis, J. P., de Frutos, A. M., Bennouna, Y., Blindheim, S., Myhre, C. L., Zibordi, G., Wehrli, C., Kratzer, S., Hakanson, B., Carlund, T., de Leuww, G., and Herber, A.: Overview of sun photometer measurements of aerosol properties in Scandinavia and Svalbard, Atmos. Environ., 52, 18-28, https://doi.org/10.1016/j.atmosenv.2011.10.022, 2011.

Walker, J. H., Saunders, R. D., Jackson, J. H., and McSparron, D. A.: Spectral irradiance calibrations, National Bureau of Standards Special Publication 250-20 Natl. Bur. Stand. (U.S.), Spec. Publ. 250-20, 102 pp., CODEN: XNBSAV, available at: https://nvlpubs.nist.gov/nistpubs/Legacy/SP/ nbsspecialpublication250-20.pdf (last access: 3 March 2018), 1987.

Wehrli, C.: Calibrations of filter radiometers for determination of atmospheric optical depth, Metrologia, 37, 419-422, 2000.
Wehrli, C.: GAWPFR: a network of aerosol optical depth observations with Precision filter radiometers, in: WMO/GAW Experts Workshop on a Global Surface Based Network for Long Term Observations of Column Aerosol Optical Properties Technical Report, GAW Report No. 162, WMO TD No. 1287, 2005.

Wehrli, C. J.: Remote sensing of Aerosol Optical Depth in a Global surface network, Diss. ETH No. 17591, available at: http://e-collection.library.ethz.ch/view/eth:30693 (last access: March 2018), 2008.

WMO: Aerosol measurement procedures, guidelines and recommendations, GAW Report 153, WMO/TD-No 1178, available at: https://library.wmo.int/opac/index.php?lvl=notice_display\&id= 11085\#.WpqIOOdG1PY (last access: 3 March 2018), 2003.

WMO: WMO/GAW Experts workshop on a global surface-based network for long term observations of column aerosol optical properties, GAW Report 162, WMO/TD-No 1287, Davos 2004, edited by: Baltensperger, U., Barries, L., and Wehrli, C., available at: https://library.wmo.int/opac/index.php?lvl=notice_ display\&id=11094\#.WpqIledG1PY (last access: 3 March 2018), 2005. 